NBER WORKING PAPER SERIES

WHICH PARTS OF GLOBALIZATION MATTER FOR CATCH-UP GROWTH?

Paul M. Romer

Working Paper 15755

http://www.nber.org/papers/w15755

\author{
NATIONAL BUREAU OF ECONOMIC RESEARCH \\ 1050 Massachusetts Avenue \\ Cambridge, MA 02138 \\ February 2010
}

I would like to thank Daron Acemoglu, Philippe Aghion, Brandon Fuller, Tim Kane, and Dani Rodrik for helpful comments. The views expressed herein are those of the author and do not necessarily reflect the views of the National Bureau of Economic Research.

NBER working papers are circulated for discussion and comment purposes. They have not been peerreviewed or been subject to the review by the NBER Board of Directors that accompanies official NBER publications.

(C) 2010 by Paul M. Romer. All rights reserved. Short sections of text, not to exceed two paragraphs, may be quoted without explicit permission provided that full credit, including $\odot$ notice, is given to the source. 
Which Parts of Globalization Matter for Catch-up Growth?

Paul M. Romer

NBER Working Paper No. 15755

February 2010

JEL No. F1,I1,O1,O33

\begin{abstract}
$\underline{\text { ABSTRACT }}$
Economists devote too much attention to international flows of goods and services and not enough to international flows of ideas. Traditional trade flows are an imperfect substitute for flows of the underlying ideas. The simplest textbook trade model shows that a welfare-enhancing move toward freer flows of ideas should be associated with a reduction in conventional trade. The large quantitative effect from the flow of ideas is evident in the second half of the 20th century as the life expectancies in poor and rich countries began to converge. Another example comes from China, where authorities dramatically reduced accident rates by adopting rules of civil aviation that were developed in the United States. All economists, including trade economists, would be better equipped to talk about international flows of technologies and rules if they adopted a consistent vocabulary based on the concepts of nonrivalry and excludability. An analysis of the interaction between rules and technologies may help explain important puzzles such as why private firms have successfully diffused some technologies (mobile telephony) but not others (safe municipal water.)
\end{abstract}

\author{
Paul M. Romer \\ Stanford Institute for Economic Policy Research \\ Stanford University \\ Stanford, CA 94305 \\ and NBER \\ paul.romer@stanford.edu
}




\section{Flows of Ideas}

In his Ely Lecture, Stanley Fischer split globalization into noneconomic and economic interactions that extend across borders. "Economic globalization, the ongoing process of greater economic interdependence among nations, is reflected in the increasing amount of cross-border trade in goods and services, the increasing volume of financial flows, and the increasing flows of labor.” Charles Jones and I have recently argued that we can take the analysis one step deeper (Jones and Romer, 2010.) Globalization is driven by the gains from reuse of ideas. Flows of ideas are the part of globalization that matters for poverty reduction and catch-up growth, yet most economists still shy from talking about them because they have trouble finding the right words.

\section{Evidence on Health and Globalization}

Angus Deaton is not shy. "The life expectancy of the vast majority of mankind, whether they life in rich or poor countries, depends on ideas, techniques, and therapies developed elsewhere...” (Deaton, 2004.) Moreover, as he and others have observed, the gain from reuse of these ideas is too large to ignore.

In a comparison across countries, Bourguignon and Morrison (2002) show that for most of the twentieth century, poor countries were catching up with rich countries in terms of life expectancy even as they fell farther behind in per capita income. They use a simple method to value increases in life expectancy and add this to conventional income per capita. Worldwide inequality in conventionally measured income grew throughout the 20th century but inequality in their life-expectancy-inclusive measure of full income peaked soon after World War II. 
Becker, Philipson and Soares (2005) provide more detailed and conservative estimates of the value of reductions in mortality and come to similar conclusions. Between 1960 and 2000, the countries with the poorest half of world population started at an average income per capita of about $\$ 900$ (in 2000 international dollars). In the next 40 years, average income per capita increased by $\$ 2200$ dollars. Life expectancy increased from 41 to 64 years, which they equate to an increase in the flow of income of about $\$ 1500$ by the end of the period. Their ending measure of full income is $\$ 4600$ instead of $\$ 3100$, higher by almost half again. Magnitudes this large matter for their own sake. They are comparable to the estimates of the direct benefits from trade in goods and services. They also have important implications about the role of policy in stifling or encouraging these gains.

Prior to reading these papers, my implicit model of development allowed for the usual gap between the world stock of technologies $T^{*}$ and the stock $T$ in a poor country. A country specific factor $R$ (for rules) influenced the rate at which ideas from the rest of the world entered the local economy. With good rules, $T$ could catch-up with $T^{*}$ very quickly. With bad rules, $T$ might not grow at all. As a result, variation in $R$ can explain the wide variation in the rate of growth that we see for poor countries. This kind of model is a reasonable first cut at the data. It tells us that we should be clear about why rules, and the incentives they create, can influence the growth in $T^{*}$ at the technological frontier and growth in $T$ as it catches up with $T^{*}$. But the health data shows that this one-dimensional model misses important interactions. There are different types of technologies $T$ that have different interactions with rules. Rules may let the technologies that reduce mortality flow into a poor country even as they keep out other technologies that can lift income per capita. 
To capture the potential benefits from globalization, we need a better understanding the differences between these types of ideas and how they interact with various local systems of rules. In our pursuit of this understanding, the models that we use to argue for ever more trade in goods and services do more harm than good.

\section{Textbook Trade Theory}

The standard textbook treatment of comparative advantage and the gains from trade relies on a single factor, labor, and two representative outputs, such as meat and potatoes. Suppose, however, that we call the two outputs lower blood pressure and lower cholesterol. In the rich country, one worker can produce pills that generate 10 units of either output. In the poor country, which uses labor to produce older generation pharmaceuticals that are less effective, one worker can produce 5 units of lower blood pressure or 3 units of lower cholesterol.

As usual, we can use this set up to show how trade in pills can raise worldwide health compared to autarky, but if we framed it this way, it would spoil the whole show. Trade in pills is an obvious sign of inefficiency. The efficient form of trade would have the workers in the poor country making pills that use the same formulas as the workers in the rich country. If the rules in these two countries give workers in the poor country access to the formulas for the pills at no charge, we would have large gains from globalization and no conventional trade in goods or services.

Just to make sure that I am not cited by the thought police, this does not show that trade restrictions are good. Nor does it show that intellectual property rights are bad (or good). It does show that we need a richer vocabulary, one that can allow for the possibility that such ideas as the formula for a pharmaceutical can also flow across a border. If flows of conventional goods 
and services are the only things we see and describe, we will miss the deeper forces and sometimes get the sign wrong. More conventional trade can be a sign of something wrong: inefficiently low cross-border flows of ideas.

\section{Examples and Phrase Book}

A persistent problem in the discussion about ideas and impediments that limit flows of ideas is ambiguity about whether reuse is actually inefficient because it is so costly or is efficient but prevented by bad rules. Here’s a typical exchange. Argument: "Poor countries should be using the knowledge that exists in the rest of the world." Counterargument: "The knowledge is already available to them but they don't know how to use it.” Clear language and microfoundations based on specific examples are the best way to resolve these ambiguities.

The chemical formula for a therapeutic compound that reduces cholesterol or blood pressure is a real example of a specific idea. The formula for oral rehydration therapy (ORT) is an idea that played a very important role in increasing life expectancy in poor countries. Estimates suggest that ORT saves between 3 and 5 millions of lives each year. It is also a useful counter example to the claim that we cannot track flows of ideas. You can now go the World Development Indicators Database and get data on the fraction of children with diarrhea who are treated according to its therapies. Coverage is sparse, but will surely get better.

In the discussion that follows, it will be useful to have other contrasting types of ideas. The first pair comes from utilities. The ideas required to deliver mobile telephony pose an interesting contrast with the ideas behind municipal systems that deliver chlorinated water. Another pair is from transportation. The first idea is congestion pricing for roads, the second a 
rule requiring that pilots and air traffic controllers use a very specific set of English phrases to communicate with each other.

The motivation for this last rule is obvious. Pilots and controllers use an agreed upon phrasebook because doing so avoids the ambiguities that arise in unstructured conversations. When a pilot “declares an emergency” to a controller with precisely those words, both sides, and all other pilots on the same frequency, know exactly what the legal and procedural implications are.

Economists could benefit from the same kind of structure in their conversations about ideas. It is an inefficient use of mental energy to have economists using vague terms or, worse still, a phrase like public good that means different things to different people. There is a simple and well-established vocabulary for structuring the discussion of the ideas and we should stick to it.

The most important concept, developed by people working in public finance, is the dichotomy between rival and nonrival goods. By now, surely every economist can repeat the definition. But lest you forget, there's a simple test that covers the important cases. If you can explain it on the phone, present it in a lecture, describe it on paper, or send it over the Internet, it is nonrival. The formula for a new pharmaceutical is a nonrival good. The formula for ORT is also a nonrival good.

The second, and logically independent concept is that of excludability. The laws in rich countries allow for patents that make the formula for a new chemical entity partially excludable. For a limited period of time, some uses of the formula are not permitted without the permission of the owner. Some workers make outdated pills, not because it is impossible to make the new 
pills in their country, but because the rules do not let them. The formula for ORT is both nonrival and nonexcludable. No one has the legal right to exclude others from following its instructions.

The concepts of rivalry and excludability (and their opposites) are all we need to describe ideas. Associated terms like spillovers, externalities, and even public good, mean different things to different economists and are best avoided.

Human capital is a term that is used elastically, but it is too good to give up. Here, microfoundations point the way to unambiguous usage. Human capital is made of meat. Meat is excludable. Meat is rival. As others have noted ${ }^{1}$, it is a puzzle how meat produces ideas that are written in books, described in lectures, and send over the internet, but it is not one that we need to dwell on here.

Reasonable people can differ about how important nonrival goods are in practice. This is neither a semantic or philosophical question. We can resolve this disagreement by looking at evidence such as avoided deaths from diarrhea and measures of the spread of new treatment protocols. (Or we can just have Angus Deaton do this for us.) If there are nonrival goods, there are gains from sharing them globally.

Reasonable people can also differ about the optimal degree of excludability to assign to any particular type of nonrival good. For the purposes at hand, all that matters is that existing legal protections, combined with secrecy, make many nonrival goods at least partially excludable, so the incentives faced by people with the ability to exclude others will influence the spread of ideas.

\footnotetext{
${ }^{1}$ See http://www.terrybisson.com/page6/page6.html for the pioneering exploration of this puzzle.
} 


\section{Technologies and Rules}

The ideas behind congestion pricing and air traffic communication differ from the ideas behind pharmaceuticals and ORT. To recognize this difference, it helps to partition ideas into technologies and rules.

Technologies are ideas about how to rearrange inanimate objects. The chemical structure of a compound, and the instructions about the chemical reactions needed to make it, are technologies. So are the instructions for rehydrating someone with diarrhea. A technology is something that would be valuable to a Robinson Crusoe who lived alone.

Rules specify how people interact with other people. The phrase book for aviation specifies the rules of communication between pilots and controllers. Congestion pricing systems specify rules that determine who drives on the road.

A bit of formalism can suggest how these concepts interact. Write output $\mathrm{Y}$ as a function

$$
Y=A\left(T\left(T^{*}, R\right), R\right) F(.)
$$

The function $A($.$) captures the factors that determine productivity. The function F($.$) is a$ conventional production function, homogeneous of degree 1 in the standard rival inputs, such as physical capital, skilled labor, and unskilled labor.

The notation for productivity suggests that it depends on local stocks of technological ideas $T$ and local rules $R, A(T, R)$. With different rules, different technologies will maximize productivity. With different technologies, different rules will be efficient.

The local stock of ideas depends, in turn, on the stock of technologies in the rest of the world and on the local rules $T\left(T^{*}, R\right)$. Because the foreign technologies $T^{*}$ are nonrival, it is 
possible for $T$ to equal $T^{*}$. However, because components of $T^{*}$ have some degree of excludability, the technologies that are actually available for local production will depend on the incentives created by the local rules $R$.

\section{Interactions Between Rules and Technologies}

With these examples and this vocabulary, we can now go beyond the simple claim in the beginning, that catch-up growth is driven by the introduction of pre-existing nonrival ideas into a poor country.

The most obvious and immediate point is that the rules $R$ are themselves nonrival ideas that can be copied from abroad. The example of the aviation phrase book is drawn from recent developments in China. ${ }^{2}$ In the 1990s, after a period of rapid expansion, Chinese airlines were arguably the most dangerous in the world. After a crash in 1994, Boeing began offering free training courses to controllers and airline personnel. With the help of Boeing and later the FAA, the Chinese civil aviation authority entirely rewrote its rulebook.

For rules as for technologies, incentives matter. The offer of assistance from the FAA was welcomed in part because Chinese authorities knew that the FAA might disqualify Chinese airlines from landing in the US and might pressure US carriers not to affiliate with Chinese partners that have substandard safety records. A deadline created by the 2008 Olympics added urgency to the Chinese efforts.

The incentive for Boeing (and later Airbus) to assist in changing the rules in China is clear. Both manufacturers had investments in specific technologies $T^{*}$ that were complementary

\footnotetext{
${ }^{2}$ Pasztor, Andy. "Flight Plan: How China Turned Around A Dismal Air-Safety Record; Foreign Help Combined With Willful Regulator; FAA Chief's Hairy Ride.” Wall Street Journal (Eastern Edition). New York, NY: October 10, 2007. A1.
} 
with the formal rules $R^{*}$ adopted by the FAA and its European counterparts. With different rules in China, the social and private value of these technologies would have been lower. Given the technologies, the manufacturers and the FAA had an incentive to change the rules $R$ in China so that $R=R^{*}$.

Because of their efforts, the accident rate in China is down by a factor of 10 and is now among the lowest in the world. Nevertheless, misunderstandings still cause avoidable close calls and authorities in China and the US continue to push for more rigid adherence to the phrase book for radio communication.

Incentives influence changes in rules just as they influence changes in technology. For many rules, a key difference compared to technologies is that large fractions of the population have to agree to a rule change. A few early adopters could buy and use fax machines or modems, but if some pilots and controllers try a new language, there will be strong restoring forces that resist the change. With more people involved and more consensus required, change comes more slowly.

Congestion pricing is a notable case of new rules that have successfully been tried in some locations but which have generally not been copied despite the large social gains that they offer. But just as some legal rules on property rights are more likely to lead to the implementation of new technologies, some political rules may be more likely to lead to Pareto improvement in other the rules. For example, the citizens of Stockholm adopted a road congestion plan by agreeing in advance to try the proposed system for seven months, going back to the status quo ante, and then having a referendum on whether to bring the system back. (Bjorn Harsman and John Quigley, 2009.) 
The two-step process followed in Sweden, with a trial period followed by a decision about whether to continue, may have broad applicability, but the details clearly matter. Something very close to this was used in Argentina to change the delivery system for water. An extensive privatization implemented by the Menem government was associated with extensions of service and reductions in infant mortality (Sebastian Galiani, Paul Gertler, and Ernesto Schargrodsky, 2005)). Nevertheless, a subsequent government was able to mobilize widespread public support for renationalization (Rafael Di Tella, Sebastian Galiani, and Ernesto Schargrodsky, 2008.)

This failure does not seem to be a fluke. Private firms have not been particularly successful at introducing modern water technologies to poor countries where they could clearly save lives. These technologies, $T^{*}$, which developed in a context with effective rules $R^{*}$ for regulating private monopolies, were badly matched to rule systems $R$ that did not have the same capacity for regulation. The cost of introducing the appropriate rule systems may also be too expensive to justify an investment in a change of rules by a water company comparable to the kind of investment undertaken by Boeing in changing the rules of civil aviation.

The remarkable and surprising worldwide spread of mobile telephony is a striking contrast. Private, for-profit firms have been very effective as a mechanism for extending the delivery of telephony services. This success does require shipments of handsets and radio transmitters across international boundaries, but these flows of physical goods are incidental to the much more important ideas about how to set up and operate phone systems that foreign firms and local entrepreneurs have now taken to virtually every country in the world. In this case, the technology that developed in rich countries allowed some element of competition in delivery. In countries where the rules for local utility regulation were not well enough developed to let 
privatization be politically viable for land-line telephony or municipal water, the potential for competition offered by the technologies of mobile telephony may have been the key to spread of the technology by private firms. In this case, $T^{*}\left(R^{*}\right)$ fortuitously turned out to be well matched to the local rules $R$.

Finally, in the very poorest countries, the successes in public health that rely on rules that look like the ones we use in science or open source software development offer another sharp contrast to the failure of most market-based methods. There clearly are some ideas that can enter from the rest of the world and raise the quality of life even in cases where the local systems of rules are farthest away from the ones we take for granted in the modern market-based systems. Without changing the basic working assumption that modern systems based on markets and the rule of law are the desired end state, we may want to ask whether there are more opportunities to spread truly life changing ideas like ORT using provisional mechanisms that may be better tuned

to the local rules. Even in the poorest countries, there have been real successes along side of the familiar failures. Perhaps there we can learn something by studying the successes.

\section{Two Types of Errors}

How we think is influenced by what we teach, and what we teach about the gains from globalization may do more harm than good. It encourages two types of errors. It suggests that technologies cannot be copied and that rules are easy to copy. In each case, it would be more accurate to say that incentives matter. Rules matter because they change both the incentives for flows of technologies and the productivity of technologies that are available locally.

Stable systems of rules are hard to change, even when the environment changes and they are no longer optimal, because it is costly to reach consensus and coordinate a change. 
Innovations in meta-rules, the rules for changing rules, would be particularly valuable if they made it easier for groups of people to transition from an existing set of rules to better ones that that have been shown to work elsewhere. 


\section{References}

Becker, Gary S., Tomas J. Philipson, and Rodrigo R. Soares. 2005. “The Quantity and Quality of Life and the Evolution of World Inequality.” American Economic Review, 95(1): 277-291.

Bourguignon, François, and Christian Morrisson. 2002. "Inequality Among World Citizens: 1820-1992.” American Economic Review, 92(4): 727-744.

Deaton, Angus. 2004. "Health in an Age of Globalization.” In Brookings Trade Forum: 2004, ed. Carol Graham and Susan M. Collins, 83-130. Washington, DC: Brookings Institution Press.

Fischer, Stanley. 2003. “Globalization and Its Challenges.” American Economic Review, 93(2): $1-30$.

Galiani, Sebastian, Ernesto Schargrodsky, and Rafael Di Tella. 2008. "Reality Versus Propaganda in the Formation of Beliefs About Privatization.” NBER Working Paper w14483.

Harsman, Bjorn and John M. Quigley. 2009. "Political and Public Acceptability of Congestion Pricing: Ideology and Self-Interest.” Institute of Business and Economic Research Working Paper W09-005.

Jones, Charles I., and Paul M. Romer. 2010. “The New Kaldor Facts: Ideas, Institutions, Population, and Human Capital.” American Economics Journal: Macroeconomics. 2(1): 224245. 